\title{
EVALUATION OF PATIENT SATISFACTION WITH MANDIBULAR SCREW RETAINED HYBRID PROSTHESIS VERSUS MANDIBULAR IMPLANT OVER-DENTURES RETAINED BY TELESCOPIC ATTACHMENTS
}

\author{
Khaled Aziz* and Mohamed Farouk Abdalla**
}

\begin{abstract}
A comparative study regarding patient satisfaction between telescopic retained implant overdenture supported prosthesis and screw retained hybrid prosthesis rehabilitation in patients with an edentulous mandible. The evaluation of the patient satisfaction was tested using a quantitative method, by asking patients different questions in a questionnaire. After a follow -up period from 2 weeks, to 12 months in both groups; there was no statistically significant difference after 3 months as well as from 3 to 6 months and from 6 to 9 months. There was also no statistically significant difference from 9 to 12 months; Patients were equally satisfied with both prostheses.
\end{abstract}

KEY WORDS: Patient satisfaction, implants- overdenture, telescopic crown, screw retained.

\section{INTRODUCTION}

Patients with conventional denture mostly complain from denture retention and stability specially the mandibular denture, due to the inability to function with the mandibular prostheses resulted from the mobility of the floor of the mouth, the alveolar ridge which is lined with thin mucosa, smaller supporting area and movement of the mandible ${ }^{1}$. Normally, the critical concerns for most denture-wearing patients relate to the appearance, speech, mastication and occlusal functions ${ }^{2}$.

There are different modalities of treatment for mandibular edentulous ridge to overcome these problems as implant supported overdenture which are considered a common treatment modality for mandible which increase support and stability and restore functions with high rate of success.

The use of four intra-foraminal implants as support for mandibular overdentures, whether splinted or unsplinted, is well noted in the literature. Many attachment systems can be utilized for retention and load distribution, especially telescopic attachments which have proven efficiency in such concerns. ${ }^{3-8}$

\footnotetext{
* Ass. Prof, Prosthodontic Department New Giza University

** Ass. Prof, Prosthodontic Department Cairo University
} 
The choice between the use of a fixed or removable restorations supported by implants in edentulous situations, is dependent on several factors including, lip support, maintanence, oral hygiene, patient force factors and others. ${ }^{9}$

Fixed restorations supported by implants usually fall under two main categories, according to the method of fixation on the abutments, cement retained and screw retained restorations. Screw retained restorations have shown over the years' successful results, regarding load distribution and retrievability.

Some authors have argued that fixed retained restorations showed better patient acceptability than removable restorations, especially in mandibular edentulous situations, however other authors have argued that oral hygiene measures and cost are also factors that are also affecting patient satisfaction regarding removable restorations. This is clearly a question worth acknowledging in clinical practice, when all factors are equal, which treatment modality would the patient be more satisfied with, a fixed or a removable choice. ${ }^{10} 11$

\section{MATERIAL AND METHODS}

The study protocol was approved by the Ethical committee of oral and dental medicine CairoUniversity. Twenty completely edentulous patients of age range of more than 40 years with maximum age of 65 were selected according to settled inclusion and exclusion criteria to participate in this study. All the participants signed their written consent after being informed about the study. The patients were clinically randomized into two groups. Group (A) received removable implant supported overdenture retained by telescopic attachments on four implants (B) received screw retained hybrid prosthesis over four implants.

Allocation of the patients in either study group or control group were performed with computerized random allocation program. Each patient was allocated a number from sequentially numbered opaque sealed envelopes when they were seen for consent and initial records where the service will not realize the patient code until patient has been recruited in the trial. Allocation concealment was ensured as the randomization table will be kept with the study coordinator and the surgeon will be informed about patient allocation at the day of the surgery. A preoperative CBCT scan was taken for the patient's mandibular arch with a scan appliance using PLANMECA Pro max 3D mid CBCT machine. The resultant image was obtained as DICOM (digital imaging and communications in medicine) data on a compact disc. After CBCT scan, the DICOM images were then imported in blue sky software (Blue sky Bio,LLC. planning software) before surgery starts.

Virtual planning was made in the intra foraminal area. Root form, tapered threaded dental implants were placed with size $3.5 \times 11.5 \mathrm{~mm}$ for the anterior site and $3.5 \mathrm{X} 10 \mathrm{~mm}$ for the posterior site (Neo Biotech Co. Ltd, Seoul, Korea).

Three months later, healing abutments were screwed with collar height $5 \mathrm{~mm}$ to allow for proper gingival healing around the implants. The healing abutments were then left for a week to allow proper healing prior making the impression. The impression was made with an open tray splinted implant level impression technique. For telescope and hybrid prosthesis fabrication a UCLA cast able abutment were used (New Biotech ISUCH400, Korea), adjusted to the available restorative space to required length, contour.

For group (A); the resultant wax abutment were casted into Co-cr abutment with a $2^{\circ}$ taper, the height of the abutment ranged between $5-7 \mathrm{~mm}$ according to the available restorative space. The resulted primary telescopic abutment were scanned to design the wax pattern of the secondary coping and 
the framework using the CAD/CAM, then casted. Primary coping were tried in patient mouth placed by using a jig to probably locating them screwed and torqued to $25 \mathrm{NM}$. Framework with secondary coping were tried onto the primary coping, when passivity was confirmed; jaw relation was taken to set-up the denture teeth. Try-in for the waxedup denture was made followed by insertion for the final prosthesis. the patients were also provided with a maxillary conventional denture. Patients were instructed to use their dentures for a period of two weeks as an adaptation period before starting satisfaction evaluation. Fig 1

For group (B) The resultant wax abutment were attached for the framework and casted to co-cr screw retained framework, and covered with porcelain opaque layer for esthetic reasons and checked for passivity, using the one screw test technique. Jaw relation record and try in were made before final delivery to the patient, the patients were also provided with a maxillary conventional denture. Patients were instructed for the importance of oral hygiene and mouth care while using their dentures in the adaptation period before evaluation. Fig 2,3

Patient's satisfaction was measured by using questionnaire $^{12}$ (Yu-Hwa Pan, et al, 2014) for the periods of 2 weeks post-delivery as a base line, then; 3 months, 6 months, 9 months and 12 months. Questionnaire was translated into Arabic language to match the language and environmental background of the patients. It was divided into three categories questions, the first section was a direct question to the patient answered by one of some choices, and each choice had a number which will be summed up and giving a score. It should be noted that regarding functional complaint and masticatory ability the higher the score the more the functional complaint and the higher the masticatory ability. On the other hand regarding overall satisfaction the higher the questionnaire score the less the patient

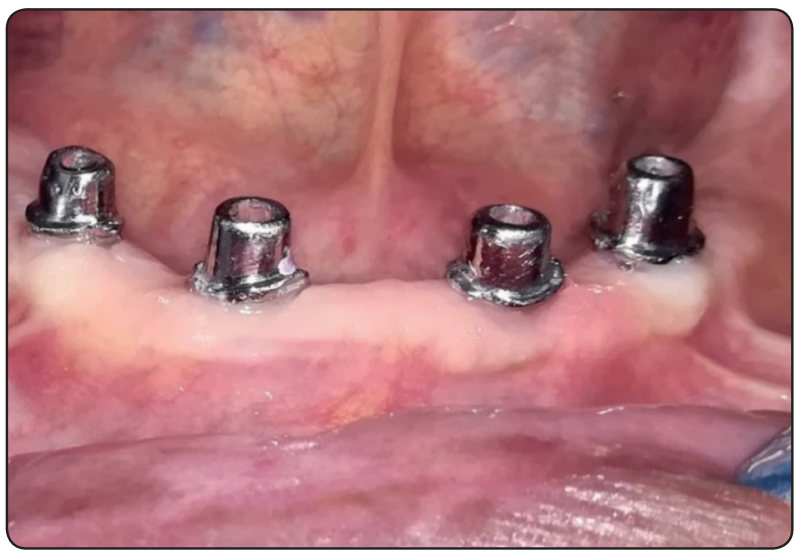

Fig. (1) Telescopic Overdenture

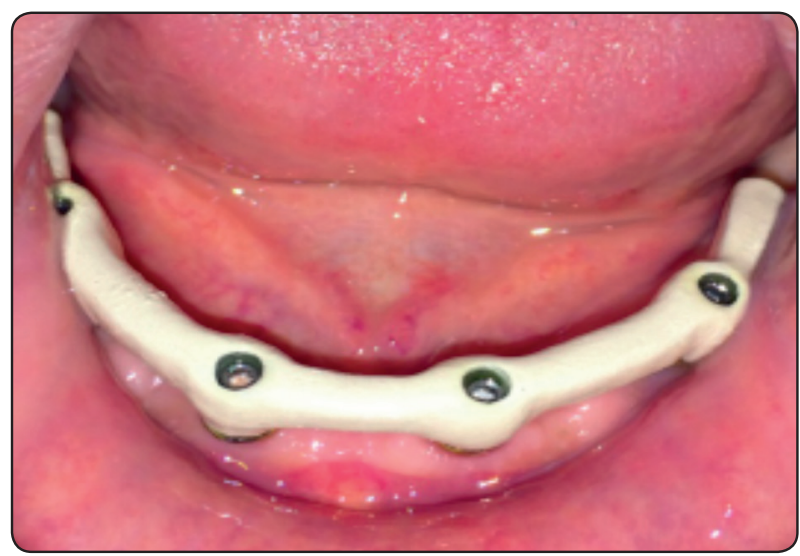

Fig. (2) Screw Retained framework (With Opaque Coating)

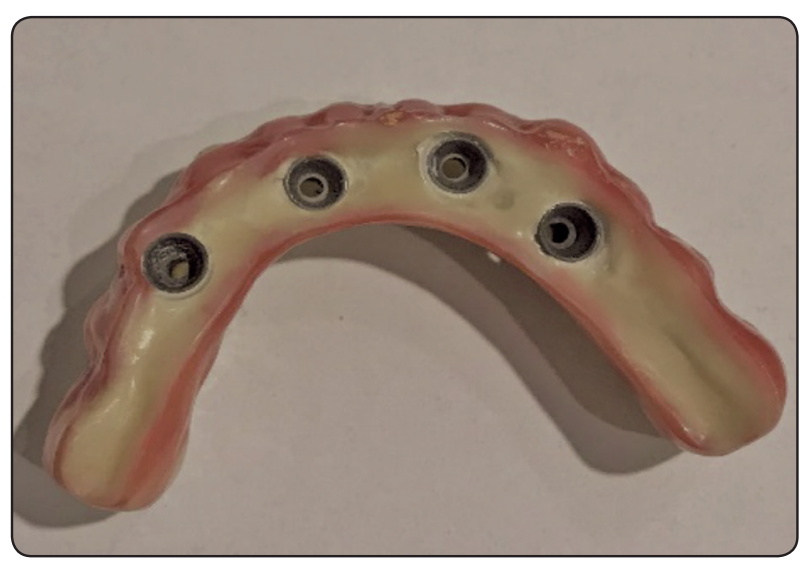

Fig. (3) Screw Retained Hybrid Prosthesis. satisfaction. Fig 4 


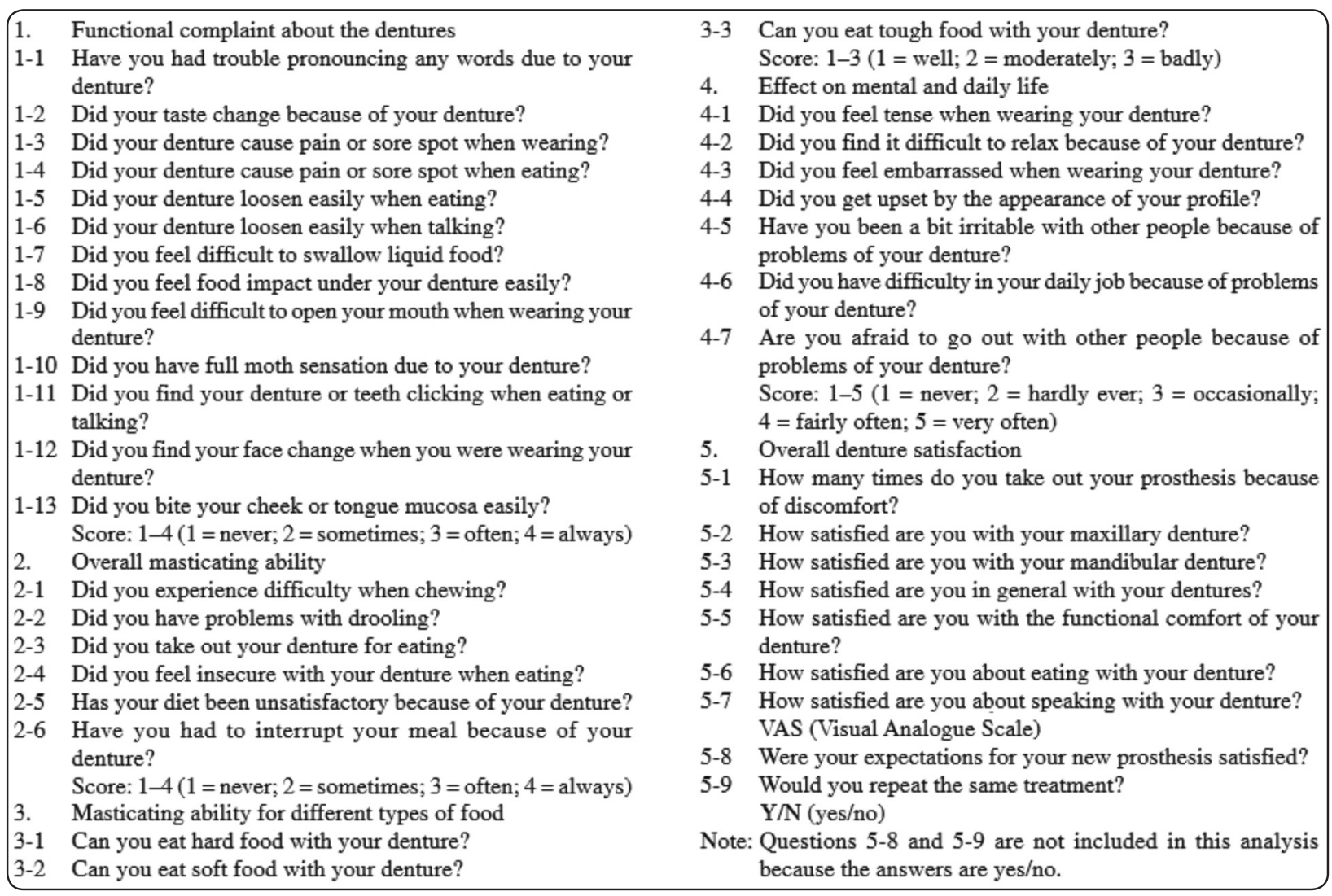

Fig. (4) Patient Satisfaction Questionnaire

\section{Statistical analysis}

The mean and standard deviation values were calculated for each group in each test. Data were explored for normality using Kolmogorov-Smirnov and Shapiro-Wilk tests, data showed non-parametric (not-normal) distribution.

Mann Whitney test was used to compare between two groups in non-related samples.

The significance level was set at $\mathrm{P} \leq 0.05$. Statistical analysis was performed with IBM ${ }^{\circledR}$ SPSS $®$ Statistics Version 20 for Windows

\section{RESULTS}

On analyzing the domains of the questionnaire the following were noted and demonstrated:

\section{Functional complaint}

There was no statistically significant difference was found between (Telescopic overdenture) and (Screw retained fixed restoration) where during the follow up period till the 12 month where $(p=0.248)$ at the two week, $(p=0.243)$ after three months.

After 6 months follow up the $p$ value was $(p=0.356),(p=0.655)$. for 9 months and finally $(p=0.439)$. for the 12 month

\section{Masticatory ability}

No statistically significant difference was found between (Telescopic overdenture) and (Screw retained fixed restoration) where $(p=0.304)$. at 2 weeks, $(p=0.900)$. for 3 months, $(p=0.222)$ for 6 months, $(p=0.063)$. for 9 months and $(p=0.052)$. for 12 months . 
TABLE (1): The mean, standard deviation (SD) of functional complain in different groups.

\begin{tabular}{|c|c|c|c|c|c|}
\hline \multirow{3}{*}{ Variables } & \multicolumn{4}{|c|}{ Functional complain } & \multirow{3}{*}{ p-value } \\
\hline & \multicolumn{2}{|c|}{$\begin{array}{c}\text { Telescope } \\
\text { (Removable) }\end{array}$} & \multicolumn{2}{|c|}{$\begin{array}{c}\text { Fixed (Screw } \\
\text { retained) }\end{array}$} & \\
\hline & Mean & SD & Mean & SD & \\
\hline After 2 weeks & 29.50 & 2.08 & 26.25 & 4.65 & $0.248 \mathrm{~ns}$ \\
\hline After 3 months & 23.00 & 2.16 & 20.75 & 3.30 & $0.243 n s$ \\
\hline After 6 months & 16.50 & 2.38 & 15.75 & 2.22 & $0.356 n s$ \\
\hline After 9 months & 11.00 & 0.82 & 11.00 & 2.16 & $0.655 n s$ \\
\hline After 12 months & 10.25 & 0.50 & 10.25 & 1.89 & $0.439 n s$ \\
\hline p-value & \multicolumn{2}{|c|}{$0.004 *$} & \multicolumn{2}{|c|}{$0.004 *$} & \\
\hline
\end{tabular}

*; significant $(p<0.05)$ ns; non-significant $(p>0.05)$

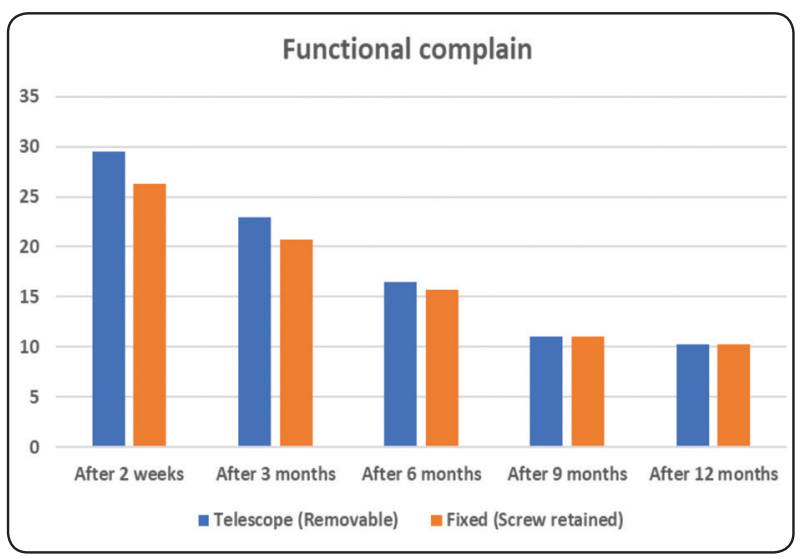

Fig. (5): Bar chart representing functional complaint for different groups

\section{Overall satisfaction results:}

No statistically significant difference was found between (Telescopic overdenture) and (Screw retained fixed restoration) where $(p=0.253)$.

The highest mean score (Least satisfaction) was found in (Telescope), while the lowest mean score (Highest satisfaction) was found in (Screw).
TABLE (2): The mean, standard deviation (SD) of masticatory ability for different groups.

\begin{tabular}{|c|c|c|c|c|c|}
\hline \multirow{3}{*}{ Variables } & \multicolumn{4}{|c|}{ Masticatory ability } & \multirow{3}{*}{ p-value } \\
\hline & \multicolumn{2}{|c|}{$\begin{array}{c}\text { Telescope } \\
\text { (Removable) }\end{array}$} & \multicolumn{2}{|c|}{$\begin{array}{c}\text { Fixed (Screw } \\
\text { retained) }\end{array}$} & \\
\hline & Mean & SD & Mean & SD & \\
\hline After 2 weeks & 16.00 & 1.83 & 17.25 & 1.71 & $0.304 n s$ \\
\hline After 3 months & 10.40 & 0.58 & 10.50 & 1.29 & $0.999 \mathrm{~ns}$ \\
\hline After 6 months & 8.50 & 0.58 & 9.25 & 0.96 & $0.222 \mathrm{~ns}$ \\
\hline After 9 months & 6.50 & 0.58 & 8.25 & 0.96 & $0.063 n s$ \\
\hline After 12 months & 6.25 & 0.50 & 8.00 & 0.82 & $0.052 n s$ \\
\hline p-value & \multicolumn{2}{|c|}{$0.003 *$} & \multicolumn{2}{|c|}{$0.003^{*}$} & \\
\hline
\end{tabular}

*; significant $(p<0.05) n s ;$ non-significant $(p>0.05)$

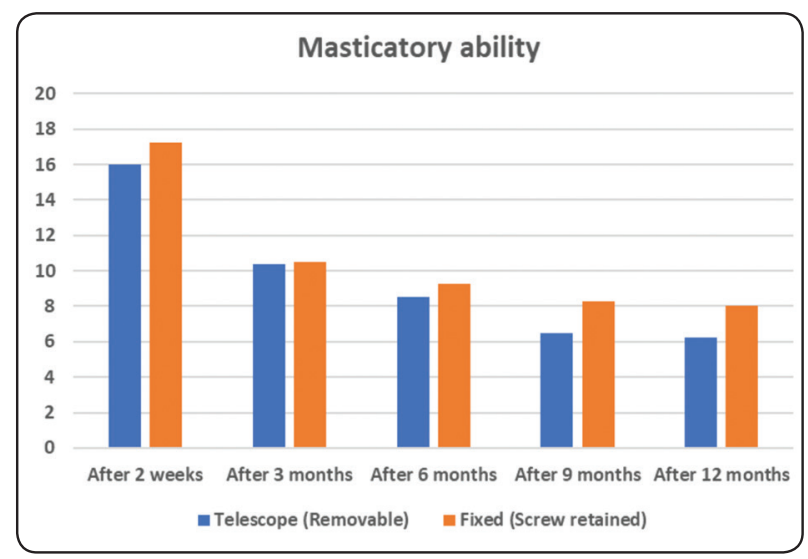

Fig. (6): Bar chart representing masticatory ability for different groups

TABLE (3): The mean, standard deviation (SD) of Overall satisfaction in different groups.

\begin{tabular}{|c|c|c|}
\hline \multirow{2}{*}{ Variables } & \multicolumn{2}{|c|}{ Overall satisfaction } \\
\cline { 2 - 3 } & Mean & SD \\
\hline Telescope & 11.20 & 6.46 \\
\hline Screw & 10.31 & 6.02 \\
\hline p-value & \multicolumn{2}{|c|}{$\mathbf{0 . 2 5 3 n}$} \\
\hline
\end{tabular}

*; significant $(p<0.05) n s ;$ non-significant $(p>0.05)$ 


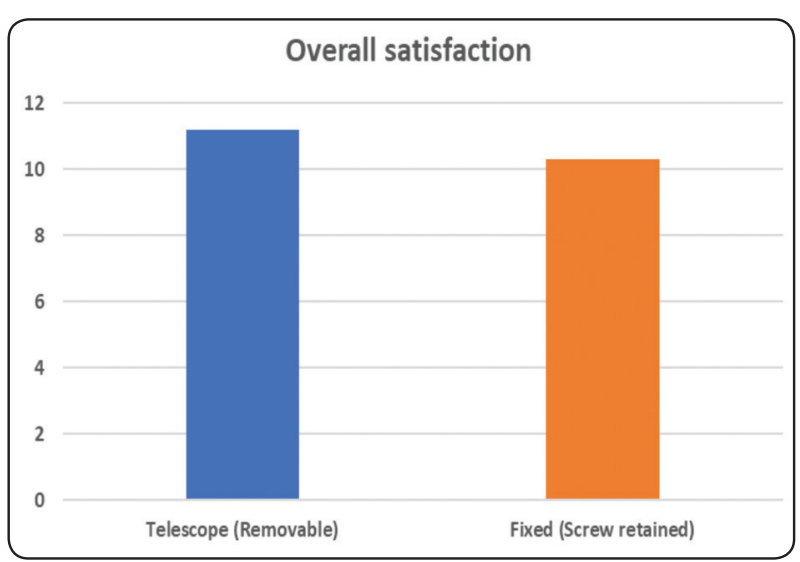

Fig. (7): Bar chart representing Overall satisfaction for different groups

\section{DISCUSSION}

In this study a subjective assessment (questionnaire) was used to compare between two different treatment modalities for mandibular implant supported restorations (overdenture and screw retained fixed restoration), the questionnaire included the three main points of high concern regarding the two modalities which are the functional complaint, masticatory performance and the overall patient satisfaction

All the results of this study revealed that there is no significant difference between removable overdenture in terms of telescopic attachment, and fixed denture in terms of screw retained hybrid prosthesis regarding functional \&masticatory ability and overall satisfaction. Although all the scores were in favor of the screw retained option, this is logically attributed to the fact that the screw retained option is a fixed option while the telescopic is still a removable one. Table1-3, fig 5-7.

This was in accordance with the result of Prithviraj D et al, when concluded that implantretained or supported prostheses giving biting force and masticatory efficiency more than conventional dentures in most of the studies. ${ }^{13}$

Heydecke et al. concluded that there is no much difference between implant supported fixed and implant supported removable prostheses; but both giving much more satisfaction in comparison to conventional complete denture but there was a significant difference regarding embarrassment at work and avoiding conversations, both for the favor of the removable group, which was also in concurrence with Stamatia et al. ${ }^{14} 15$

Grandmont et al study has mentioned that regarding fit, retention, function \& quality of life, there was no difference between both types of implant-supported groups. While Heydecke et al have found that there was a significant difference regarding embarrassment at work and avoiding conversations, both in the favor of the removable group. Ortensi, et al in a five-year retrospective follow up also found that ball abutments are quite satisfactory 161417

On the other hand, Misch et al, emphasized that stability and chewing ability had higher scores for the fixed prosthesis than the removable in the lower jaw. Patients often need a fixed prosthesis to feel teeth integrity as a part of their mouth which cannot be provided through a removable prosthesis. Such enhancement has a positive dramatic effect on improving masticatory efficiency. ${ }^{18}$

A systematic review was made 2016 clarifying that fixed prostheses showed higher scores in the mandible regarding stability, ability to chew, aesthetics and ability to speak. ${ }^{19}$

Another systematic review has revealed conflicting results where it seems that removable restorations are more favorable to patients in the maxilla and provide better hygiene. On the other hand, mandibular fixed restorations are more stable. ${ }^{20}$

However, it is worth noting that in all test subjects the opposing occlusion was a denture, hence the increased chewing ability of fixed restoration opposing another fixed restoration was not present. As a result the functional, chewing ability and overall patient satisfaction were nearly the same in both groups, with no statistical significant differences. 


\section{CONCLUSION}

There was no statistical significant difference in patient satisfaction between implant supported overdentures and screw retained fixed restorations in edentulous mandibular cases.

\section{REFERENCES}

1. Heckmann SM, Schrott A, Graef F, Wichmann MG, and. Weber HP, Mandibular two-implant telescopic overdentures. Clinical oral implants research 2004; 560: 569-15.

2. Allen PF, McMillan AS, Walshaw D. A patient-based assessment of implant-stabilized and conventional complete dentures. J Prosthet Dent 2001; 141:147-85.

3. Daniela M, Cristina T \& Teodora P. Attachment systems for implant overdentures: A literature review. Rom J Oral Rehabil. 2014;6; 51-56.

4. D Krishna Prasad, D Anupama Prasad, Manan Buch. Selection of attachment systems in fabricating an implant supported overdenture. Journal of Dental Implant . 2017;4:176-181.

5. Frisch E, Ratka-Krüger P\& Lehmann KM. Clinical outcomes of implant-supported and rigidly double crownretained prostheses in edentulous mandibles: An 8-year retrospective study. Z Zahnärztl Implant. 2014;30:113127.

6. Laverty DP, Green D, Marrison D, Addy Land Thomas MBM. Implant retention systems for implant-retained overdentures. Brit Dent J. 2017; 222:347-359.

7. Yunus et al. Patient-Based and Clinical Outcomes of Implant Telescopic Attachment-Retained Mandibular Overdentures: A 1-Year Longitudinal Prospective Study. The International Journal of Oral \& Maxillofacial Implants. 2014;29: 1-7.

8. Ziwei Y, Tomoya G, Yoshinobu M, Ying, Z Gonda T, Maeda Y.Influence of Attachment Height and Shape on Lateral Force Transmission in Implant Overdenture Treatment. Int. J.Prosthodont . 2017;30: 586-591.

9. Raghoebar GM, Meeijer HJ, Slot W, Slater JJ, Vissink A. A systematic review of implant-supported overdentures in the edentulous maxilla, compared to the mandible: how many implants. Eur J Oral Implant. 2014; 7:191-201.
10. Yao C J , Cao C, Bornstein MN, Mattheos N Patientreported outcome measures of edentulous patients restored with implant- supported removable and fixed prostheses: A systematic review .Clin Oral Impl Res. 2018;29: 241-254

11. Gurgel BCV, Pascoal ALB, Souza BLM, Dantas PMC, Montenegro SCL, Oliveira AGRC, Calderon PS. Patient satisfaction concerning implant-supported prostheses: An observational study. Braz Oral Res.2015; 29:1-6.

12. Yu-Hwa Pan, et al. Implant-supported mandibular overdenture versus complete denture. Biomed J. 2014 ; 37 : 159-162.

13. Prithviraj D, Madan V, Harshamayi P, Gyan C, Kumar, Vashisht R. A comparison of masticatory effi ciency in conventional dentures, implant retained or supported overdentures and implant supported fixed prostheses: A literature review. Journal of Dental Implants 2014 ; 4 (2)

14. Heydecke G, Boudrias P, Awad MA, et al. Within-subject comparisons of maxillary fixed and removable implant prostheses. Clin Oral Impl Res. 2003; 14:125-30

15. Stamatia L, Athina L, Maria T. Importance of patient satisfaction Measurement and electronic surveys. Int $\mathrm{J}$ of health research and Innovation. 2013;1:67-87.

16. Ortensi L, Martinolli M, Borromeo C, Ceruso FM, Gargari M, Xhanari E, et al. Effectiveness of ball attachment systems in implant retained- And supported-overdentures: A three- And five-year retrospective examination. Dent J. 2019;7(3):1-9.

17. De Grandmont P, Feine JS, Taché R et al. Within-subject Comparisons of Implant-supported Mandibular Prostheses: Psychometric Evaluation. J Dent Res. 1994; 73(5): 1096104. PMid: 8006237

18. Misch CE, Goodacre CJ, Finley JM et al. Consensus conference panel report: crown-height space guidelines for implant dentistry-part 2. Implant Dent. 2006; 15(2):113-21

19. Selim K, Ali S, Reda A, Implant Supported Fixed Restorations versus Implant Supported Removable Overdentures: A Systematic Review. Open Access Maced J Med Sci.2016.

20. Kern.Js, Kern .T, Wolfart.S, Heussen.Na A systematic review and meta-analysis of removable and fixed implantsupported prostheses in edentulous jaws: post-loading implant loss. Cl.Oral.Impl.Res. 2015;27(2):174-195 